road to the New Jerusalem! In this country, so far as I am aware, there have been only three cases where the suffrage has been changed from a broader to a narrower basis. In early Massachusetts, it was limited by a vote of all the colonists to church members and property owners; in New Jersey, woman suffrage was abolishcd early in the nineteenth century; and in Rhode Island, the property-owning qualification of $\$ 75$ was recently raised to $\$ 300$.

In my opinion, we never shall have good government until the suffrage is limited to those having a certain education, or paying a certain tax; perhaps also allowing those to vote who are willing to pay a fee for the privilege. We never shall have good financial management in cities where, as in Boston, 118,000 non-taxpayers spend the money of 18,000 tax-payers. For, taking things on the average, as we always have to do in sociological questions, the liability to a tax implies a certain measure of success and ability. That is why the Bolshevist, who is a mentally and nervously irritable person, filled with hate in the form of envy, is so against property as an institution.

Limitation of the suffrage may seem impossible of accomplishment in these times, when we are seeking the smallest possible political unit, even as we try to split up the atoms of physical matter; and yet, if everyone would speak out who desires it, the achievement might not be so remote. Perhaps the most pregnant saying of Goethe, which embodied a generalization from his wide study of biology and other sciences, was that anything to succeed must have "Beschraenkung"-limitation. Goethe was not what I have called an expansile. $\mathrm{He}$ would doubtless have recognized that the chief danger of the American people today is the tendency to follow out logically abstract ideals without reference to the concrete situation. This, as LeBon has shown, is a tendency indigenous to the Latin but not to the Nordic spirit. We are developing it partly through the dilution of our national character by immigration, and partly by hearkening to the catchwords of expansile leaders and those who wallow in humanitarian platitudes.

Therefore we should all be grateful to Mr. Ireland for stating the case so clearly, and for his testimony to the value of aristocracy, based on his long and thorough study of various experiments in government.

\title{
Plant Breeder's Envelope
}

The plant breeder's envelope, described in the following paragraph, worked admirably on tender succulent flax plants and ought to be of use for other delicate plants. It has the advantages of being light in weight, insect proof, moisture proof, and of being readily adapted and used. (Fig. 6.)

A piece of oiled paper is folded or doubled the desired width, with an additional inch or two which is to be left unstitched to facilitate opening the envelope. A sewing machine is used to stitch off as many envelopes as the length of the folded sheet will permit. The envelopes are cut apart with scissors and slit up through the middle of the unstitched portion at the base. At the crotch of this slit a hole is cut of sufficient size for the plant stem to fit snugly when enclosed. One half, sec- tion $B$, of the unstitched portion is folded lengthwise towards the top of the envelope. The other half, section $A$, is folded on a forty-five degree slant over the first half. Points $c, d$, and e coincide, and at this corner where the folded parts overlap a snap fastener such as is used on women's dresses is used to fasten the envelope base together. The plant breeder's envelope is now in the same position as when enclosing an emasculated flower on the stem of a plant. The unstitched portion at the envelope base must be one-half, or less than one-half, the width of the envelope in length so that, when folded, there will be no unstitched portion above the fold. RoBert L. DAVIS, Scientific Assistant, Fiber Investigations, $U . S$. Department of Agriculture, ITashington, $D . C$. 


\section{PLANT BREEDER'S ENVELOPE}

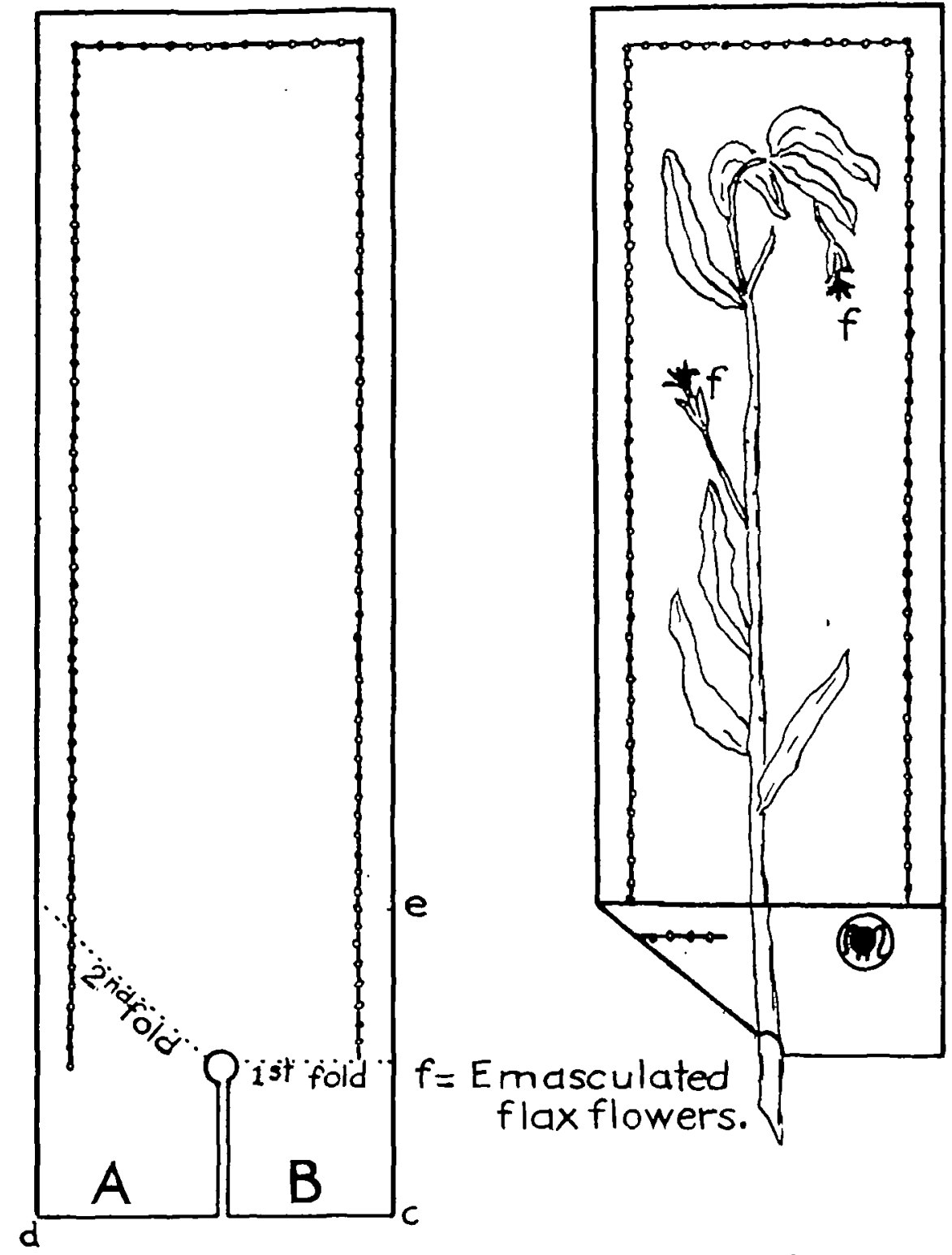

A PRACTICAL ENVElope for PLANT hreEders

It has the advantage of being light in weight, insect proof, moisture proof, and of being readily adapted and used. See description on opposite page. (Fig. 6.) 